\title{
Incentivos económicos a la renovación de alojamientos turísticos: el mercado de derechos materializables en plazas alojativas
}

\author{
María Candelaria SANTOS CHINEA \\ Máster en Dirección y Planificación del Turismo y Doctoranda en Turismo \\ Universidad de La Laguna \\ csantoschinea@gmail.com \\ Moisés R. SIMANCAS CRUZ \\ Profesor Titular de Geografía Humana \\ Departamento de Geografía \\ Universidad de La Laguna \\ msimancas@ull.es \\ Raúl HERNÁNDEZ MARTÍN \\ Profesor Titular de Economía Aplicada, \\ Director de la Cátedra de Turismo CajaCanarias-Ashotel \\ Universidad de La Laguna \\ rahernan@ull.es
}

Recibido: 10-01-2013

Aceptado: 21-01-2013

\begin{abstract}
RESUMEN
La estrategia actual de ordenación del turismo en Canarias se articula en torno a la renovación de áreas y alojamientos turísticos susceptibles de ser calificados como obsoletos. Para ello, la Ley 2/2013, de 29 de mayo, de renovación y modernización turística de Canarias contempla incentivos dirigidos a hacer atractivas las operaciones de renovación que trasciendan la mera rehabilitación de los alojamientos turísticos. Asimismo, plantea mecanismos dirigidos a fomentar y hacer viable económicamente los procesos de sustitución de tales establecimientos. Uno de estos mecanismos se vincula con la obtención de derechos a materializar plazas turísticas adicionales derivadas de la ejecución de un proyecto de renovación edificatoria. La relevancia de este incentivo radica en que la ley prevé fuertes restricciones a la construcción de nuevos alojamientos. En este artículo analizamos las implicaciones en forma de debilidades y oportunidades, del mercado que surge a partir de estos derechos materializables en plazas adicionales.
\end{abstract}


Palabras clave: Destinos maduros, establecimientos de alojamiento, incentivos económicos, Islas Canarias, política turística, renovación.

\title{
Economic incentives to renovation in tourism accommodation: The market of building rights
}

\begin{abstract}
Current tourism policy in Canary Islands revolves around the renovation of both, areas and tourist accommodations that could be classified as obsolete. The legislation provides a package of incentives aimed at making attractive renovation operations that go beyond mere rehabilitation of hotels. It also includes mechanisms to promote and to make economically viable replacement processes of these establishments. One of these mechanisms is related to obtaining building rights that can be used to build new tourism accommodation places as an incentive for the implementation of an accommodation renovation project. Theses building rights are not affected by the quantitative restrictions to the development of new hotels that are applied in the Canary Islands. In this paper we analyze the weaknesses and opportunities arising from the market of building rights in tourism accommodation.
\end{abstract}

Keywords: mature destinations, tourist accommodation, economic incentives, Canary Islands, tourism policy, renovation.

Sumario: 1. Introducción. 2. El objeto del mercado: los derechos materializables en plazas alojativas resultantes de procesos de renovación edificatoria. 3. Implicaciones de la creación del mercado de derechos materializables en plazas alojativas resultantes de procesos de renovación. 4. Conclusiones.

\section{INTRODUCCIÓN}

La renovación de los destinos turísticos se ha convertido en uno de los temas más relevantes en la actualidad en el sector turístico. Esto es así en la medida en que muchos destinos, particularmente aquellos que se beneficiaron del impulso del turismo durante los años sesenta, setenta y ochenta del siglo XX se encuentran en la actualidad en una etapa de madurez o estancamiento vinculada, entre otros factores, a la obsolescencia de su planta de alojamiento. La evolución de los destinos turísticos ha sido un tema muy estudiado $\mathrm{y}$ que ha dado lugar a diversos planteamientos $\mathrm{y}$ conceptos. Según el modelo del ciclo de vida de Butler (1980) Canarias se podría encontrar en una fase de estancamiento o incluso declive, mientras que otros autores como Knowles y Curtis (1999) se refieren a esta fase como de post-estancamiento. El 
desarrollo de políticas públicas para afrontar estas situaciones ha tenido gran importancia en el mundo, destacando el caso de los destinos costeros del Mediterráneo (Farsari, Butler y Prastacos, 2007).

La política turística de Canarias (España) ha convertido la renovación en una estrategia fundamental y prioritaria, a medio y largo plazo. A su vez, la estrategia de renovación se ha diseñado paralelamente y de forma complementaria a la limitación o moderación cuantitativa del crecimiento de la capacidad alojativa turística. La limitación al crecimiento de la planta alojativa en Canarias se planteó a partir del Decreto 4/2001, de 12 de enero, por el que se acordó la formulación de las Directrices de Ordenación General y las del Turismo (DOT en lo sucesivo), iniciándose un proceso de regulación pública de la oferta de alojamiento turístico y del suelo turístico por parte del Gobierno de Canarias. Esta regulación se concretó con la Ley 19/2003, por la que se aprueban las Directrices y la Ley 6/2009, de 6 de mayo, de medidas urgentes en materia de ordenación territorial para la dinamización sectorial y la ordenación del turismo. Este dilatado y complejo proceso de regulación sigue en vigor en la actualidad, tras la aprobación de la Ley $2 / 2013$, de 29 de mayo, de renovación y modernización turística de Canarias. Todo este conjunto de normas conforman la ordenación del turismo que se conoce coloquialmente como moratoria turística canaria.

La renovación edificatoria (física) de la oferta de alojamiento turístico inadecuada como se califica en la DOT 3.b) no sólo constituye un deber de sus titulares, sino que, en el caso de Canarias, es obligatoria. Asimismo, la renovación es clave para que los establecimientos turísticos que la regulación canaria denomina como en situación de deterioro o de obsolescencia (Ley 6/2009). La calificación de deterioro implica una falta de conservación, menoscabo y quebranto de los elementos estructurales y accesorios tanto del edificio, como de las instalaciones o dotaciones técnicas y el equipamiento turístico complementario, de ocio, salud o deportivo del mismo. Por su parte, la obsolescencia supone un grado de inadecuación a la ordenación turística vigente $o$, en general, a la normativa que fuera de aplicación, en lo relativo a la funcionalidad, seguridad, habitabilidad o calidad ambiental del propio edificio, del equipamiento turístico complementario de ocio, salud, deportivas o de esparcimiento o de las instalaciones técnicas. La renovación adquiere una mayor relevancia, si cabe, considerando la información derivada del proyecto de I+D+i ReinvenTUR (García Cruz, 2014): el $81 \%$ de los 1.880 establecimientos alojativos identificados en las islas consolidadas turísticamente se construyeron con anterioridad a 1995. Aunque no existe una coincidencia entre antigüedad y obsolescencia, en la mayoría de las ocasiones existe una relación directa.

En general, no se dispone $-\mathrm{o}$, al menos, no han trascendido públicamente- de informes técnicos sobre los efectos, positivos y negativos de la aplicación de la política pública de renovación edificatoria en Canarias, si bien algunos trabajos académicos han abordado la cuestión (Chinchilla, 2009; Dorta, 2013; García Cruz, 2010; Llorca y Sosa, 2010; Simancas, 2010, 2011 y 2012; Simancas y García, 2010). La conclusión de 
estos trabajos es que la renovación ha tenido más sombras que luces. Entre las razones de este fracaso destaca sobremanera la cuestión del alto coste económico de tales operaciones. Por ejemplo, en el Avance del Plan Territorial Especial de Ordenación Turística Insular de Gran Canaria (2006) se estimó que las inversiones mínimas por plaza para establecimientos de 1 llave y 1 ó 2 estrellas, 2, 3 y 4 llaves serían de 10.000 , $12.000,14.000$ y 16.000 euros, respectivamente. Así, aunque la experiencia determina que este tipo de operación de renovación requiere de un programa específico de incentivos de carácter económico, fiscal, laboral y administrativo, el Gobierno canario no lo ha planteado, con el consiguiente incumplimiento de lo previsto al respecto en las Directrices 18.3 y 31.3 .

Desde el principio de internalización de costes, los costes correspondientes a las operaciones de renovación edificatoria de los alojamientos turísticos deben ser asumidos por sus titulares o responsables, como se plantea en la propia Memoria de las Directrices de Ordenación: "La dotación de equipamientos, infraestructuras y servicios constituye un aspecto clave que distingue un enclave turístico de otro, lo que exige a la Administración cubrir los déficit que aparezcan, sin internalizar los costos causados por el crecimiento, de forma los agentes privados contribuyan a dichos gastos". Así, en coherencia con lo que se indica plantea en el Preámbulo de la Ley estatal 8/2013, de 26 de junio, de rehabilitación, regeneración y renovación urbanas, estos incentivos suponen una compensación de esa asunción prácticamente exclusiva. Ello resulta más apropiado en un momento de retraimiento del crédito como el actual y de reducida capacidad de financiación pública, vía subvenciones. Además, adquiere una mayor relevancia en el caso de la oferta alojativa extrahotelera, en cuanto la normativa actual impide que pueda acogerse a incentivos fiscales o subvenciones al carecer de una forma jurídica societaria, ya que la mayoría son comunidades de propietarios que tienen cedida la explotación a una tercera empresa.

Si bien cualquier empresario puede optar por la renovación de su establecimiento turístico siguiendo los trámites administrativos convencionales, la citada Ley 6/2009 articuló un procedimiento y, sobre todo, un conjunto de incentivos. Estos se han ampliado en la Ley $2 / 2013$, con el fin de hacerla más atractiva. Estos incentivos se fundamentan, sobre todo, en la posibilidad de otorgar un determinado número de lo que hemos denominado como plazas premio, en cuanto se conceden en proporción a la capacidad alojativa original del establecimiento objeto de renovación.

Este mecanismo se revela fundamental por dos razones. En primer lugar, porque la renovación edificatoria constituye la clave para la obtención de nuevas autorizaciones turísticas - entendido como el acto administrativo preceptivo que verifica y determina la compatibilidad del uso turístico de un establecimiento con la ordenación territorial turística y la normativa sectorial aplicable- . Esto es particularmente importante en un momento de prohibición del otorgamiento de nuevas autorizaciones, prohibición de la que solamente ha quedado fuera la construcción de hoteles y apartamentos de cinco estrellas o superior. En segundo lugar, porque la Ley 6/2009 desarrolló un mecanismo ya previsto de forma embrionaria en la Ley 19/2003 y que la Ley 2/2013 consolida 
para los promotores que no quieran o puedan materializarlas; nos referimos a la enajenación o patrimonialización de tal derecho. Con ello se ha habilitado un mercado de derechos materializables en plazas alojativas o instalaciones complementarias. El principal objetivo de este trabajo es analizar las implicaciones, en forma de debilidades y oportunidades, de este mercado.

Tras esta introducción en el siguiente epígrafe se exponen los aspectos más destacados de los derechos materializables en plazas alojativas en Canarias según la ley 2/2013. Posteriormente, se analizan las implicaciones y se hace una valoración del instrumento, el mercado de derechos materializables en plazas alojativas, que se deriva de la mencionada ley. Para finalizar, se expondrán algunas conclusiones.

\section{EL OBJETO DEL MERCADO: LOS DERECHOS MATERIALIZABLES EN PLAZAS ALOJATIVAS RESULTANTES DE PROCESOS DE RENOVACIÓN EDIFICATORIA}

La obsolescencia de alojamientos turísticos individuales tiene un efecto negativo sobre la competitividad del destino, su imagen y el nivel de satisfacción de los clientes. Es decir, desde una perspectiva económica se producen externalidades negativas desde las empresas con peor imagen sobre el resto del sector. Es por ello que resulta necesaria la toma de decisiones al respecto desde las administraciones públicas, lo cual es una tarea compleja. Por un lado, no tiene fundamento que la administración financie procesos de renovación hotelera en beneficio de empresarios privados individuales. Por otra parte dejar al libre mercado las decisiones de renovación puede conducir a situaciones de deterioro progresivo. Es por ello que en Canarias se idea un sistema de incentivos a la renovación que, sin un coste directo e inmediato para las arcas públicas, pueda contribuir a que empresas obsoletas $\mathrm{y}$, generalmente, poco rentables, puedan acometer procesos de renovación. Este mecanismo consiste, en un contexto de restricciones legales a la expansión turística en la concesión, bajo ciertas condiciones, de derechos materializables en nuevas plazas alojativas a aquellos promotores que lleven a cabo un proceso de renovación edificatoria de sus establecimientos.

Los mercados de derechos no son, ni mucho menos, exclusivos del alojamiento turístico. Existen otros ejemplos de actividades económicas en las que se emplean. Entre ellos destaca su utilización como instrumento de regulación de aspectos medioambientales. Sirva como ejemplo el comercio de derechos de emisión de gases de efecto invernadero en España. Como indica el Ministerio de Agricultura, Alimentación y Medio Ambiente, se encuentra regulado por la Ley 1/2005, de 9 de marzo y se puso en marcha el 1 de enero de 2005. El objetivo es, a través de la fijación de un tope máximo de emisiones que se ponen en circulación, reducir las emisiones de $\mathrm{CO}_{2}$ en los sectores industriales y de generación eléctrica. Se trata por tanto, de un incentivo, o desincentivo, económico cuyo objetivo es obtener un beneficio medioambiental, en este caso la reducción de emisiones contaminantes a 
la atmósfera. Teniendo en cuenta las diferencias entre ambas actividades, de manera similar al mercado de emisiones, el mercado de derechos materializables en plazas alojativas se convierte en un instrumento por el que se crea un incentivo económico que, en este caso, tiene por objetivo favorecer la renovación de los establecimientos de alojamiento. En el mercado de derechos materializables en plazas alojativas el techo de plazas no es una cantidad fijada previamente, sino que estará determinada por las operaciones de renovación llevadas a cabo en los establecimientos de alojamiento.

En esta dirección, la Ley 6/2009 desarrolló un mecanismo ya previsto de forma embrionaria en la 19/2003 y que la Ley 2/2013 consolida para los promotores que no quieran o puedan materializar las plazas premio; nos referimos a la enajenación o patrimonialización de tal derecho. Con ello se ha habilitado un mercado de derechos materializables en plazas alojativas o instalaciones complementarias. Éste se nutre de las plazas turísticas que resultan de tres tipos de operaciones de renovación edificatoria: a) la remodelación edificatoria; b) la demolición (sustitución) y traslado (total o parcial) de la capacidad alojativa hacia otras áreas no consolidadas; y c) la implantación y ejecución de nuevos equipamientos públicos o, en el caso de ser declarados de interés general por el Gobierno de Canarias, nuevos equipamientos privados.

La remodelación de los establecimientos implica el reciclaje de los alojamientos turísticos y, por tanto, un aprovechamiento del valor de la oferta de alojamiento turístico existente (Simancas, 2010). Es importante hacer notar que no se trata de mera rehabilitación edificatoria, que comprendería la obra menor o de estricto mantenimiento (conservación). Esta última se requiere imperativamente por la Administración competente al propietario o titular de un establecimiento ya autorizado y en funcionamiento (artículo 9.1, del Texto Refundido de la Ley de Suelo, aprobado por Real Decreto Legislativo 2/2008, de 20 de junio).

En el caso de la reforma, se aprovechan los elementos estructurales y accesorios del edificio pero se produce una modernización estética (ornato) y, sobre todo, la actualización y mejora de las unidades alojativas y de los espacios comunes. De este modo, mientras éstas mantienen las características tipológicas y funcionales básicas del inmueble, se aborda una modificación en profundidad de los elementos menos duraderos (instalaciones, pavimentos, acabados, carpinterías interiores y exteriores, sanitarios y otros). Las reformas de mayor calado implican, incluso, un cambio estructural del inmueble, incluyendo la reducción del número de unidades alojativas y, por ende, de plazas.

En el artículo 13 de la Ley 2/2013 se establecen los porcentajes relativos a las plazas premio que pueden obtenerse a partir de las operaciones de renovación. Así, la renovación de un establecimiento turístico que cumpla con la inversión mínima por plaza establecida en la propia ley y cuya categoría final sea de cuatro estrellas o superior en el caso de establecimientos hoteleros o tres estrellas o superior en el caso de establecimientos extrahoteleros, dará derecho a obtener hasta un $50 \%$ de plazas adicionales. 
Cuadro 1. Proporción de plazas nuevas de los alojamientos turísticos por cada plaza preexistente sustituida

\begin{tabular}{|c|c|c|c|c|c|c|c|}
\hline \multirow{2}{*}{$\begin{array}{l}\text { Uso del } \\
\text { solar } \\
\text { resultante } \\
\text { de la } \\
\text { operación } \\
\text { de } \\
\text { sustitución }\end{array}$} & \multirow{2}{*}{$\begin{array}{c}\text { Ley } 19 / 2003 \text {, } \\
\text { por la que se } \\
\text { aprueban } \\
\text { las } \\
\text { Directrices } \\
\text { de } \\
\text { Ordenación } \\
\text { y las } \\
\text { Directrices } \\
\text { de } \\
\text { Ordenación } \\
\text { del Turismo } \\
\text { de Canarias } \\
\text { (Directriz } \\
\text { 19) }\end{array}$} & \multicolumn{2}{|c|}{$\begin{array}{c}\text { Ley } 6 / 2009 \text {, de medidas } \\
\text { urgentes en materia de } \\
\text { ordenación territorial para } \\
\text { la dinamización sectorial y } \\
\text { la ordenación del turismo } \\
\text { (artículo 13) } \\
\end{array}$} & \multicolumn{4}{|c|}{$\begin{array}{l}\text { Ley } 2 / 2013 \text {, de renovación y modernización turística de Canarias } \\
\qquad \text { (artículo 17) }\end{array}$} \\
\hline & & $\begin{array}{c}\text { Sin } \\
\text { incremento } \\
\text { de } \\
\text { categoría } \\
\text { del } \\
\text { establecimi } \\
\text { ento en } \\
\text { relación } \\
\text { con el } \\
\text { reemplazado }\end{array}$ & $\begin{array}{l}\text { Incremento } \\
\text { de categoría } \\
\text { del } \\
\text { establecimiento } \\
\text { en relación } \\
\text { con el } \\
\text { reemplazado }\end{array}$ & $\begin{array}{c}\text { Sin } \\
\text { incremento } \\
\text { de categoría } \\
\text { del } \\
\text { establecimiento } \\
\text { en relación } \\
\text { con el } \\
\text { reemplazado }\end{array}$ & $\begin{array}{c}\text { Con } \\
\text { incremento de } \\
\text { una categoría } \\
\text { del } \\
\text { establecimiento } \\
\text { en relación con } \\
\text { el reemplazado }\end{array}$ & $\begin{array}{c}\text { Con } \\
\text { incremento de } \\
\text { dos categorías } \\
\text { del } \\
\text { establecimiento } \\
\text { en relación con } \\
\text { el reemplazado }\end{array}$ & $\begin{array}{l}\text { Con incremento } \\
\text { de tres categorías } \\
\text { del } \\
\text { establecimiento en } \\
\text { relación con el } \\
\text { reemplazado }\end{array}$ \\
\hline $\begin{array}{c}\text { Se ceda } \\
\text { gratuitamente } \\
\text { al } \\
\text { Ayuntamiento } \\
\text { con destino } \\
\text { dotacional } \\
\text { o espacio } \\
\text { libre } \\
\text { público }\end{array}$ & 1,5 & 3 & 4 & 2 & 2,25 & 2,50 & 2,75 \\
\hline $\begin{array}{l}\text { Se destina } \\
\text { a oferta } \\
\text { complementa } \\
\text { ria turística } \\
\text { definida } \\
\text { como "de } \\
\text { interés } \\
\text { para el } \\
\text { área" en } \\
\text { cuestión } \\
\text { por el } \\
\text { conespondiente } \\
\text { instrumento } \\
\text { de } \\
\text { planificación } \\
\text { territorial } \\
\text { escala } \\
\text { insular }\end{array}$ & 1,2 & 2 & 3 & 1,75 & 2 & 2,25 & 2,50 \\
\hline
\end{tabular}

Fuente: Ley 19/2003, de 14 de abril, por la que se aprueban las Directrices de Ordenación General y las Directrices de Ordenación del Turismo de Canarias / Ley 6/2009, de medidas urgentes en materia de ordenación territorial para la dinamización sectorial y la ordenación del turismo / Ley 2/2013, de 29 de mayo, de renovación y modernización turística de Canarias. Elaboración propia.

En la medida en que esta posibilidad de obtener estas plazas premio en los casos de las actuaciones de remodelación edificatoria se ha limitado a las denominadas rehabilitaciones integrales de la Ley 6/2009 y totales de la 2/2013, la categoría resultante debe ser superior a cuatro y tres estrellas en establecimientos hoteleros y apartamentos, respectivamente, y, en ningún caso, inferior a la sustituida (artículo 10 de la Ley 2/2013). Esta determinación resulta coherente con la estrategia de su cualificación (excelencia) y especialización, vía modalidad y categoría, de la oferta alojativa perseguida desde el inicio del proceso de moratoria 
turística, con la pretensión de captar segmentos de mercado de mayor poder adquisitivo y potencial de crecimiento, así como garantizar mayores precios. Así, el citado porcentaje de plazas premio es susceptible de incrementarse en un $25 \%$ más por cada grado de categoría que se aumente a partir de las tres estrellas, sin que en ambos casos se supere el cien por cien de las plazas preexistentes. Ello hace que este tipo de operación posibilite incrementos de hasta un $100 \%$ en las nuevas plazas alojativas autorizadas.

Cuadro 2. Importes mínimos de inversión por plaza en establecimientos hoteleros

\begin{tabular}{|c|c|c|c|}
\hline \multirow[b]{2}{*}{ Modalidad } & \multirow[b]{2}{*}{ Categoría final } & \multicolumn{2}{|c|}{ Inversión mínima por plaza } \\
\hline & & $\begin{array}{c}\text { Decreto } 138 / 2010 \text { por el que se } \\
\text { desarrolla la previsión en materia } \\
\text { de rehabilitación de } \\
\text { establecimientos turísticos* }\end{array}$ & $\begin{array}{c}\text { Ley } 2 / 2013, \text { de } \\
\text { renovación y } \\
\text { modernización turística } \\
\text { de Canarias }\end{array}$ \\
\hline \multirow{3}{*}{ Hotelera } & 4 Estrellas & $6.143 €$ & $9.214 €$ \\
\hline & 5 Estrellas & $7.866 €$ & $11.799 €$ \\
\hline & 5 Estrellas Gran Lujo & $10.073 €$ & $15.120 €$ \\
\hline \multirow{4}{*}{ Extrahotelera } & 3 Estrellas & $4.253 €$ & $6.379 €$ \\
\hline & 4 Estrellas & $5.577 €$ & $8.366 €$ \\
\hline & 5 Estrellas & $7.142 €$ & $10.713 €$ \\
\hline & Villas & - & $8.366 €$ \\
\hline
\end{tabular}

Fuente: DECRETO 138/2010, de 23 de septiembre, por el que se desarrolla la previsión en materia de rehabilitación de establecimientos turísticos, contenida en la Ley 6/2009, de 6 de mayo, de medidas urgentes en materia de ordenación territorial para la dinamización sectorial y la ordenación del turismo.

Ley 2/2013, de 29 de mayo, de renovación y modernización turística de Canarias. Elaboración propia.

* Para determinar esa cuantía, el Decreto 138/2010 parte de un análisis del coste de construcción de obra nueva para uso hotelero y apartamentos turísticos, obteniendo el coste de construcción unitario por categoría, al cual se ha deducido un porcentaje del $20 \%$, eliminando los gastos generales y el beneficio industrial, a los efectos de considerar el mismo como presupuesto de ejecución material. A su vez, la cuantía resultante se ha multiplicado por la superficie construida media por plaza de alojamiento para obtener el importe de obra nueva por categoría, al que se aplica un porcentaje del $30 \%$, teniendo presente el previsto para la conservación (50\%) en el artículo 153.2 del Texto Refundido de las Leyes de Ordenación del Territorio de Canarias y de Espacios Naturales de Canarias. De 
este modo, la inversión total debe calcularse dividiendo el presupuesto de ejecución material de la obra de rehabilitación, impuestos no incluidos, entre el número de plazas de alojamiento del establecimiento que se pretendan rehabilitar.

Por su parte, la sustitución edificatoria en el mismo emplazamiento implica la demolición total del edificio y el traslado, total o parcial, de la capacidad alojativa. Este traslado debe hacerse hacia solares en suelos clasificados como urbanizables, sectorizados y ordenados o urbanos categorizados para uso turístico, ubicados en espacios turísticos no consolidados o menos congestionados que el original. Esta nueva ubicación podrá estar en la misma área turística, en otra del mismo municipio, o bien en otro municipio de la propia isla. Las proporciones y supuestos de plazas premio contemplados para ambas operaciones en la Ley 19/2003 fueron ampliados en la 6/2009, llegando a triplicarse, e incluso, cuadruplicarse en función de las casuísticas contempladas en el Cuadro 1; no obstante, la Ley 2/2013 ha disminuido esos porcentajes. El promotor de esta transferencia puede ser, bien el mismo propietario si dispone de tal suelo turístico apto para ello, bien otras personas físicas y/o jurídicas con suelo turístico pero sin posibilidad de acceder a plazas alojativas como consecuencia de la aplicación de la Ley 19/2003.

Por último la Ley 2/2013 contempla, en el supuesto de implantación y ejecución de nuevos equipamientos públicos o privados, que estos últimos hayan sido declarados de interés general por el Gobierno de Canarias. En este caso se obtendrán un máximo de 1.000 plazas turísticas, a razón de una plaza por cada 30.000 euros de inversión, siempre que la inversión mínima alcance los 30 millones de euros. Este incentivo se relaciona con la saturación de las áreas turísticas canarias, especialmente las desarrolladas con anterioridad al segundo quinquenio de la década de los noventa, por un exceso de densidad edificatoria. Esta medida supuso un reconocimiento implícito de la necesidad de corregir tal déficit de equipamientos complementarios. Este déficit se debió, entre otras circunstancias, a que se optó por una oferta indiferenciada de ocio orientada fundamentalmente al descanso. Por ello, la oferta turística era de manera casi exclusiva, la de alojamiento. A su vez, el control ejercido por los grandes operadores en el diseño de los paquetes turísticos ha limitado sobremanera la posibilidad de desarrollo de una oferta de recreación diversa y, por tanto, de tales equipamientos complementarios.

\section{IMPLICACIONES DE LA CREACIÓN DEL MERCADO DE DERECHOS MATERIALIZABLES EN PLAZAS ALOJATIVAS RESULTANTES DE PROCESOS DE RENOVACIÓN}

En la medida en que las autorizaciones turísticas previas son transmisibles cuando se dan por circunstancias reales, también lo son los derechos obtenidos 
como resultado de procesos de renovación. El mercado de derechos se fundamenta en la compra-venta de estos activos transferibles, en cuanto pueden cederse a un tercero por cualquier medio admitido en Derecho. Además, los derechos no son excluyentes, es decir, los obtenidos por otros titulares no limitan los que puedan adquirirse de manera individual para una actuación de renovación concreta.

El mercado de derechos materializables en plazas aspira a que la inversión en operaciones de renovación alojativa resulte atractiva tanto para los propietarios de alojamientos obsoletos como para los empresarios interesados en construir alojamientos de cuatro estrellas. Para los propietarios de establecimientos obsoletos esto es así ya que pueden financiar los costes de rehabilitación a través de la venta de los derechos. Para los empresarios turísticos interesados en construir nuevos establecimientos turísticos de cuatro estrellas, ya que con la compra de tales derechos garantizan poder hacerlo sin necesidad de ser titular de un alojamiento que haya sido objeto de renovación previamente. Es más, a través de la acumulación de los derechos de varios titulares, podrían afrontar operaciones de mayor dimensión y que pueden resultar más rentables económicamente.

Es necesario hacer notar, en todo caso, que los mecanismos previos a la Ley 2/2013 no funcionaron y no se emplearon en ningún caso. Esto no resulta una cuestión baladí, pues a los mencionados elevados costes de la operaciones de renovación edificatoria se debe añadir la obligación de adecuarlas a inversión mínima por plaza de alojamiento fijada inicialmente en el Decreto 138/2010 y que la Ley 2/2013 ha incrementado en un 50\% (Cuadro 2). En este sentido, la venta de los derechos a la autorización de plazas adicionales podría garantizar al vendedor el capital necesario para cumplir con esta determinación.

El mecanismo de asignación y el techo de plazas alojativas materializables está relacionado directamente con el número de operaciones de renovación edificatoria acometidas, al quedar vinculado a las plazas premio derivadas de la sustitución de un alojamiento turístico o de su remodelación con incremento de categoría.

La categoría de los derechos materializables en plazas alojativas es una cuestión sujeta a cierta controversia, de modo que el mercado no está bien definido. De la lectura de la ley parece desprenderse que la única forma de materialización de estas plazas premio es en hoteles de cuatro estrellas y apartamentos de cuatro y tres estrellas. Ello se debe a que las autorizaciones turísticas previas de cinco estrellas o gran lujo se otorgan ilimitadamente sin vincularse a los procesos de renovación.

El plazo de materialización de los derechos es limitado, al caducar a los cinco años desde su preceptiva inscripción en el Registro turístico de plazas de alojamiento (artículo 20). Este registro se plantea como una sección específica del Registro General Turístico, el cual constituye un registro especial a crear por cada Cabildo Insular, que es en cuanto es la administración competente para otorgar autorizaciones previas. Los derechos a las plazas turísticas adicionales no utilizadas en la parcela objeto de remodelación o sustitución deben inscribirse obligatoriamente en el registro turístico de plazas de alojamiento. 
Otra cuestión relevante a tener en cuenta en el mercado de plazas es que su ámbito territorial es insular. De este modo, los trasvases interinsulares de derechos $-\mathrm{y}$, por ende, de plazas turísticas - no se permiten. Con ello se aclararon las dudas que surgían al respecto de la lectura del párrafo final de la Disposición Adicional Primera 3 de la Ley 19/2003. Esta limitación geográfica del mercado no sólo se debe a factores elementales de topología o a la organización política de que se ha dotado la Comunidad Autónoma sino, sobre todo, a la intención pública de que las islas no compitan turísticamente entre sí y de respetar la ordenación territorial del turismo establecida por cada Plan Insular de Ordenación. De este modo, se evitan interferencias en los techos alojativos definidos a escala insular como consecuencia de la llegada de derechos materializables en plazas turísticas procedentes de otros mercados insulares.

Una consecuencia de lo anterior es la creación de cuatro mercados (Tenerife, Gran Canaria Fuerteventura y Lanzarote) con precios diferenciados en función de dos fuerzas. Por un lado, la demanda de nuevas plazas de alojamiento turístico, vinculada con la disposición de los empresarios a comprar derechos para su materialización. Cuanto mayor sea el interés por construir nuevas plazas mayor será el precio de los derechos. Por otro lado, el precio de estos derechos se relacionará también con la oferta de un bien complementario a los derechos: la oferta de suelo turístico en el que materializar la construcción de nueva planta de alojamiento. Cuanto menor sea la oferta de este suelo mayor será el precio del suelo y de los derechos. En todo caso, podría incluso darse el caso de que resulte imposible materializar el derecho en el plazo establecido, con la consiguiente pérdida de vigencia de la autorización. En definitiva, nos encontramos con un activo con un potencial de volatilidad en cuanto a su precio muy notable, lo que podría propiciar actuaciones especulativas.

La vinculación de la construcción de hoteles nuevos de cuatro estrellas con la renovación edificatoria de las existentes se relaciona claramente con la disponibilidad de suelo urbanizable con destino turístico y urbano no consolidado existente en cada isla para acoger las plazas adicionales. Tomando como referencia la información de la Sociedad de Gestión y Planeamiento Territorial y Medioambiental del Gobierno de Canarias (Gesplan), de los $54.376 .355 \mathrm{~m}^{2}$ de suelo clasificado en 2011 en las cuatro islas turísticamente consolidadas, Lanzarote era la que acaparaba un mayor porcentaje (el $37,2 \%)$, seguida de Tenerife $(23,2 \%)$, Fuerteventura $(22,5 \%)$ y Gran Canaria $(17,1 \%)$. La disponibilidad de suelo clasificado en Canarias es susceptible de acoger 148.564 plazas turísticas, presentando una distribución insular dispar: mientras que Tenerife y Gran Canaria concentraban el mayor número de plazas potenciales $(36,2 \%$ y $35,5 \%$, respectivamente), Fuerteventura $(18,2 \%)$ y Lanzarote $(10 \%)$ eran las que acumulaban un menor volumen. Estas cifras pueden ser consideradas como el umbral máximo de plazas a incorporarse a corto, medio y largo plazo en el mercado regional e insular, como consecuencia de la estrategia de incentivo de 
plazas adicionales por renovación. Sin embargo, no todas estas plazas son susceptibles de ser ejecutadas a corto plazo. En el caso de Gran Canaria 10.536 plazas podrían materializarse a corto plazo, al tratarse de suelos que presentan un alto grado de consolidación de los servicios urbanísticos. Adicionalmente, 10.851 y 31.380 plazas podrían materializarse en dicha isla a medio y largo (más de cuatro años) plazo, respectivamente. Por su parte, en Fuerteventura podrían entrar 7.434 y 19.619 plazas nuevas en el mercado medio y largo plazo. Tenerife es, de nuevo, la isla con un mayor número de plazas turísticas sin ejecutar (37\%), seguida de Gran Canaria (36\%), Lanzarote (18\%) y Fuerteventura (9\%). Por último, en cuanto al número de plazas potenciales que podrían construirse, la cantidad ha sufrido modificaciones en los últimos cinco años: mientras Tenerife ha pasado de una disponibilidad de suelo para 163.285 plazas a 53.832, Gran Canaria apenas ha variado, pasando de 53.519 a 52.767. En resumen, el número de plazas susceptible de entrar en el mercado está limitado, especialmente a corto plazo. Estas plazas pueden ser utilizadas tanto para la construcción de establecimientos de cinco estrellas como, a través de plazas premio, ser utilizadas para la construcción de nuevos hoteles de cuatro estrellas o establecimientos extrahoteleros de tres y cuatro estrellas. El ensamble de todas estas piezas es posible que dé lugar a estrategias especulativas sobre el precio del suelo, de los derechos materializables en plazas y de los establecimientos obsoletos susceptibles de renovación. Sería deseable que las estrategias, no previstas en la ley, que se deriven de la creación de las plazas premio y del mercado asociado no desaten fuerzas que sean contraproducentes en relación a su objetivo inicial, la renovación de los destinos turísticos.

Sobre la limitación de suelo no sólo ha influido la prohibición de clasificación de nuevos suelos urbanizables con destino turístico (DOT 7.2.a), sino el retraso en la aprobación definitiva de los planes generales de ordenación. En efecto, aunque el Decreto 55/2006 impuso un máximo de dos años para la conclusión y aprobación definitiva de los mismos, a fecha de 31 de diciembre de 2013, ninguno de los diecisiete municipios turísticos (consolidado o en vía de consolidación), supuestamente los más dinámicos y los que necesitan revisar constantemente sus modelos territoriales, habían cumplido con este precepto. Tampoco se habían adaptado al Texto Refundido de las Leyes de Ordenación del Territorio y de Espacios Naturales de Canarias (TRLOTENC) y a la Ley 19/2003, con las implicaciones que ello supone, sobre todo, en relación con la inseguridad jurídica (García Márquez, 2010). Además, diez de ellos tenían un plan aprobado con anterioridad al TRLOTENC, siendo los de Guía de Isora, Arona y Haría los únicos planes generales de ordenación adaptados a las Directrices. A este respecto, resulta llamativo que la ordenación urbanística del municipio de Yaiza seguía rigiéndose por un plan general de ordenación urbana de 1973, no estando, por tanto, ni siquiera adaptado al Texto Refundido estatal de 1976, a la vez que los de Mogán, La Oliva y Teguise lo hacían por las Normas Subsidiarias aprobadas en 1998, 1991 y 2001, respectivamente. 
No solamente ha habido retrasos e incumplimientos en la aprobación de los planes generales de ordenación, lo mismo sucede con los denominados Planes de Modernización, Mejora e Incremento de la Competitividad. Se trata de novedosos, excepcionales y singulares instrumentos de gestión urbanísticos de las áreas turísticas, creados en virtud de la Ley 6/2009, con el fin de agilizar, vía convenios urbanísticos, los procesos de renovación edificatoria, supliendo, así, la indicada falta de aprobación de los planes generales de ordenación. Para ello se plantean como planes de tramitación simplificada y vigencia indefinida, cuya principal fortaleza es su ejecutividad inmediata. Sin embargo, a fecha de 28 de febrero de 2013, sólo se han aprobado definitivamente cinco de los dieciocho Planes previstos: los de Puerto del Carmen (Lanzarote) y Maspalomas Costa Canaria (Gran Canaria), Costa Teguise (Lanzarote), Corralejo (Fuerteventura) y Playa de Mogán, en virtud de los Decretos 58/2011, de 4 de marzo, 90/2012, de 22 de noviembre, 14/2012, de 17 de febrero, 15/2012, de 17 de febrero, 4/2014, de 23 de enero, respectivamente. Ello ha retrasado la ejecución de proyectos de renovación de establecimientos alojativos $\mathrm{y}$, por ende, la generación de derechos a la autorización de plazas adicionales que van a conformar el citado mercado.

Uno de los principales efectos de esta reducida disponibilidad de suelo puede ser un previsible incremento de la plusvalía de los establecimientos alojativos en las áreas turísticas congestionadas, cuyas plazas pueden ser objeto de una posible transferencia de derechos urbanísticos, así como de los solares con licencia para construir en las áreas receptoras. En ambos casos, no se trata tanto de un aumento real del valor de los inmuebles y de los terrenos urbanos, sino de un incremento artificial y especulativo, en cuanto suponen la llave para la construcción de nuevas plazas alojativas turísticas en solares aún sin edificar. No obstante, se trata de expectativas de plusvalías con amparo legal, contra las cuales la acción urbanística difícilmente puede intervenir, más allá de evitar, tanto como sea posible, la retención especulativa del suelo. En todo caso, queda por determinar si el diseño de este modelo con su alto potencial especulativo responde a las necesidades del modelo turístico, por un lado, y a las necesidades sociales de Canarias, por otro.

\section{CONCLUSIONES}

La política turística de Canarias ha convertido la renovación en una estrategia fundamental y prioritaria a medio y largo plazo. Prueba de ello es la aprobación de la Ley $2 / 2013$, de 29 de mayo, de renovación y modernización turística de Canarias. En esta ley se incluyen una serie de incentivos a la renovación de alojamientos turísticos entre los que se encuentra el derecho a obtener plazas premio procedentes de dichas operaciones. En la medida en que estas plazas adicionales son intercambiables, surge un mercado de derechos materializables en 
plazas alojativas cuyas debilidades y oportunidades han sido analizadas en este artículo.

Entre las oportunidades que proporciona este mercado destaca su posible utilización como fuente de financiación para la renovación de los establecimientos turísticos en el caso de no querer materializar en el mismo las plazas adicionales resultantes. Además, este instrumento se convierte en el único mecanismo disponible para la construcción de establecimientos de alojamiento de categoría inferior a cinco estrellas en Canarias.

El análisis del mercado de derechos materializables en plazas de alojamiento también ha puesto de manifiesto una serie de debilidades que plantea dudas acerca de su éxito como incentivo a la renovación. En primer lugar existen problemas a la hora de definir el mercado. No queda clara la categoría de los derechos, aunque en cualquier caso, solo resulta atractivo para los derechos materializables en plazas alojativas de establecimientos hoteleros de cuatro estrellas y extrahoteleros de tres y cuatro estrellas. En segundo lugar, limitar el incentivo al ámbito insular provoca que cada isla parta con unas condiciones iniciales diferentes a la hora de emplear el incentivo, permitiendo que la oferta de alojamiento se incremente más en las islas con un mayor número de camas. Además, hace que en unas islas pueda existir exceso de demanda y en otras exceso de oferta de suelo y/o de derechos, con precios diferentes (incentivos a la renovación diferentes) en función de las características de cada una de ellas y del control de los mercados de plazas por algunos agentes.

Otro aspecto relevante en cuanto puede suponer un freno al uso efectivo de este instrumento es que en Canarias la legislación en materia urbanística no se ha desarrollado plenamente. En este sentido, aunque los planes de modernización, mejora e incremento de la competitividad pueden favorecer las operaciones en las áreas donde se encuentren implantados, el problema seguirá existiendo en las zonas donde no existan, que son la mayoría.

También debe prestarse especial atención al elevado coste de las operaciones de renovación de los establecimientos de alojamiento, que además se acentúa con la Ley $2 / 2013$, ya que ésta establece un incremento del $50 \%$ en la inversión mínima por plaza renovada respecto a la legislación anterior. A esto hay que sumarle el hecho de que la actual crisis económica ha provocado que se reduzcan las posibilidades de obtener financiación para este tipo de operaciones.

Finalmente, resulta conveniente, a la hora de evaluar el posible éxito o fracaso del mercado, tener en cuenta que desde la Ley 19/2003, por la que se aprueban las Directrices de Ordenación General y las Directrices de Ordenación del Turismo de Canarias, ya existía la posibilidad de obtener e intercambiar derechos para construir nuevas plazas de alojamiento. Sin embargo, este mecanismo no llegó a utilizarse. 


\section{BIBLIOGRAFÍA}

BUTLER, RW. The concept of a tourist area cycle of evolution: implications for management of resources. Canadian Geographer, Vol. 24, no 1, 1980. p. 5-12.

CHINCHILLA PEINADO, J. A. La rehabilitación de los establecimientos turísticos alojativos como manifestación del desarrollo urbanístico sostenible: el ejemplo de Canarias. Práctica urbanística: Revista mensual de urbanismo, no 87, 2009b. p. 64-77.

DORTA RODRÍGUEZ, A. Algunos apuntes sobre la renovación hotelera como estrategia de reestructuración de destinos turísticos consolidados. Revista Turismo (Escuela Universitaria de Turismo Iriarte). Vol. 3-4, 2013 p. 33-37.

FARSARI, Y., BUTLER, R. y PRASTACOS, P. Sustainable tourism policy for Mediterranean destinations: issues and interrelationships. International Journal of Tourism Policy, 1(1). 2007. p. 58-78.

GARCÍA CRUZ, J.I. Renovación vs creación de espacios turísticos. Efectos territoriales de las Directrices de Ordenación del Turismo de Canarias. $X V$ Congreso de la Asociación Española de Expertos en Turismo. AECIT / Facultad de Ciencias Económicas y Empresariales. Universidad de La Laguna. 2010.

GARCÍA CRUZ, J.I. El impacto territorial del tercer boom turístico de Canarias. Servicio de Publicaciones de la Universidad de La Laguna. 2014.

GARCÍA MÁRQUEZ, F. La Ordenación del Territorio como práctica pública de articulación de modelos de desarrollo. En Simancas Cruz, M. R. El impacto de la crisis en la economía canaria. Claves para el futuro. Volumen II. La Laguna. Real Sociedad Económica de Amigos del País de Tenerife / Cabildo Insular de Tenerife. 2010. p. 801-842.

Gobierno de España. Ministerio de Agricultura, Alimentación y Medio Ambiente. Consulta 4 de junio de $2013<\mathrm{http}: / /$ www.magrama.gob.es/es/cambioclimatico/temas/comercio-de-derechos-de-emision/el-comercio-de-derechos-deemision-en-espana/>

KNOWLES, T. y, CURTIS, S. The market viability of European mass tourist destinations. A post- Stagnation lifecycle analysis. International Journal of Tourism Research, Vol.1, no 2. 1999. p. 87-96.

LLORCA AFONSO, E. y SOSA DÍAZ-SAAVEDRA, A. (2010): Procesos de reciclaje aplicados al turismo de masas en el Sur de Gran Canaria. Congreso Internacional Sustainable Building. 2010.

[http://www.sb10mad.com/ponencias/archivos/d/D013.pdf]

MINISTERIO DE AGRICULTURA, ALIMENTACIÓN Y MEDIO AMBIENTE. El comercio de derechos de emisión en España. Guía explicativa. 2009.

SIMANCAS CRUZ, M. R. La renovación edificatoria de la oferta turística de alojamiento en destinos consolidados: la experiencia de Canarias. Revista de Geografía (Universitat de Valencia). nº 87, 2010. p. 23-44. 
SIMANCAS CRUZ, M. R. El fracaso de la renovación de áreas turísticas consolidadas de litoral a través de la sustitución de la oferta alojativa obsoleta: la experiencia de las Islas Canarias. Cuadernos de Turismo, $\mathrm{n}^{\circ}$ 27, 2011. p. 869899.

SIMANCAS CRUZ, M. R. Evaluando políticas públicas de renovación de destinos turísticos maduros: el proceso de reconversión turística de Canarias. En VERA REBOLlO, F. y RODRÍGUEZ SÁNCHEZ, I. (eds.). Renovación y restructuración de destinos en áreas costeras. Marco de análisis, procesos, instrumentos y realidades. Colección: Desarrollo Territorial, 11. Universitat de València, pp. 2012. p. 163-200. 